\title{
ERRATUM
}

\section{China's major Late Neolithic centres and the rise of Erlitou}

Chi Zhang, A. Mark Pollard, Jessica Rawson, Limin Huan, Ruiliang Liu \& Xiaojia Tang

https://doi.org/10.15184/aqy.2019.63 Published by Cambridge University Press, 12 June 2019

In the article by Zhang et al. (2019), Figure 2 was incorrect and did not match the caption. The correct Figure 2 with matching caption is given below.

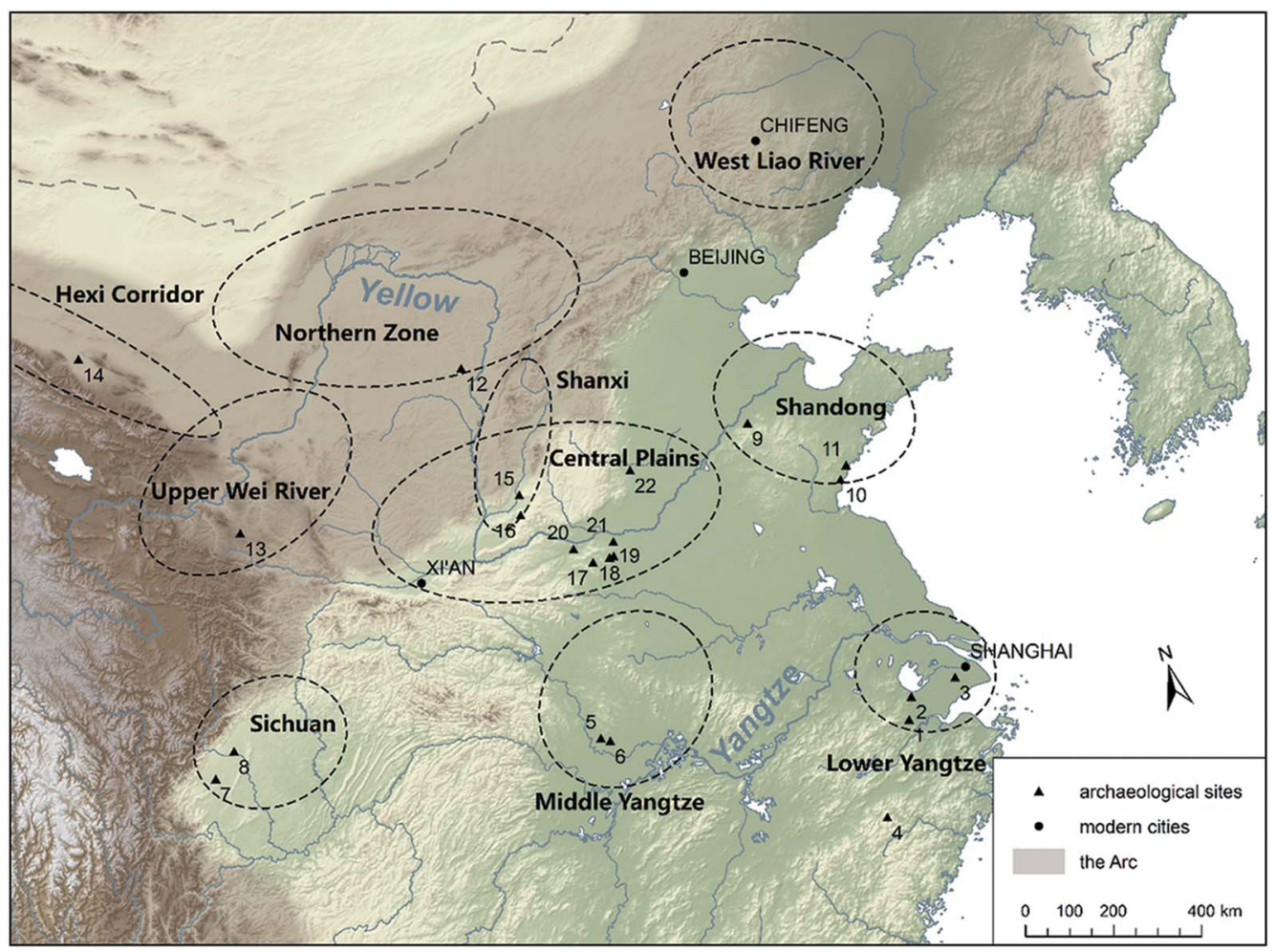

Figure 2. Distribution of major regions and sites mentioned, with the Arc shown as the shaded area: 1) Liangzhu; 2) Qianshanyang; 3) Guangfulin; 4) Haochuan; 5) Qujialing; 6) Shijiahe; 7) Baodun; 8) Sanxingdui; 9) Chengziya; 10) Yaowangcheng; 11) Liangchengzhen; 12) Shimao; 13) Yunbaoshan; 14) Xichengyi; 15) Taosi; 16) Zhoujiazhuang; 17) Wangchenggang; 18) Xinzhai; 19) Guchengzhai; 20) Erlitou; 21) Zhengzhou; 22) Anyang (figure by Limin Huan).

\section{Full citation}

Zhang, C., A.M. Pollard, J. Rawson, L. Huan, R. Liu \& X. Tang. 2019. China's major Late Neolithic centres and the rise of Erlitou. Antiquity 93: 588-603. https://doi.org/10.15184/aqy.2019.63 